Pacific Journal of Mathematics

ON POLYNOMIALS APPROXIMATING THE SOLUTIONS OF 


\section{ON POLYNOMIALS APPROXIMATING THE SOLUTIONS OF NONLINEAR DIFFERENTIAL EQUATIONS}

\section{A. Bacopoulos and A. G. Kartsatos}

Suppose that $L(x)$ is a differential operator and $R(t)$ a continuous function, and consider the differential equation (*) $L(x)=R(t)$. Then a problem in approximation theory is whether we can approximate a solution $x(t)$ of $\left(^{*}\right)$ uniformly with a sequence of polynomials $P_{n}$ for which we have $\| R(t)-$ $\left.L\left(P_{n}\right)\right) \| \leqq \eta_{n}$, where $\|\cdot\|$ is a certain norm and $\eta_{n}$ a specific sequence of nonnegative constants. This is done here for a first order nonlinear differential operator $L$ and for two different norms, the uniform norm and the $L_{p}$ norm $(1 \leqq p<+\infty)$.

Consider the differential equation:

$$
L(x) \equiv x^{\prime}+Q(t, x)=R(t)
$$

where the functions $Q, R$ are defined and continuous on $[0,1] \times(-\infty$, $+\infty)$ and $[0,1]$ respectively. Suppose also that there exists a unique solution $x(t)$ of $(1)$ satisfying $x(0)=0$. On $C[0,1]$ consider the norms:

$$
\|f\|=\sup _{t \in[0,1]}|f(t)|,\|f\|_{p}=\left[\int_{0}^{1}|f(t)|^{p} d t\right]^{1 / p}(p \geqq 1),
$$

and let

$$
\mu_{n}=\inf _{P_{n} \in \Pi_{n}}\left\|L(x)-L\left(P_{n}\right)\right\|, \mu_{n}^{*}=\inf _{P_{n}^{*} \in \Pi_{n}}\left\|L(x)-L\left(P_{n}^{*}\right)\right\|_{p},
$$

where $x(t)$ is the solution of (1) with $x(0)=0$, and $\Pi_{n}$ is the set of all polynomials of degree less than or equal to $n$, which satisfy the condition $P_{n}(0)=0$, (or $P_{n}^{*}(0)=0$ ). By (3), if $\varepsilon_{n}$, (or $\varepsilon_{n}^{*}$ ), is a sequence of positive constants such that $\lim _{n \rightarrow \infty} \varepsilon_{n}=0$, (or $\lim _{n \rightarrow \infty} \varepsilon_{n}^{*}=0$ ), then there exist sequences of polynomials $P_{n}$, (or $\left.P_{n}^{*}\right), \in \Pi_{n}$ such that

$$
\left\|L(x)-L\left(P_{n}\right)\right\| \leqq \mu_{n}+\varepsilon_{n},\left\|L(x)-L\left(P_{n}^{*}\right)\right\|_{p} \leqq \mu_{n}^{*}+\varepsilon_{n}^{*},
$$

for every $n=1,2 \cdots$.

Our aim here is to show that, for quite a large class of equations of the type (1), it is possible to have the polynomials satisfying the first or the second of (4) converge uniformly, along with their derivatives, to the solution $x(t)$ and its derivative respectively.

It should be noted that if the infimum in either one of (3) is attained for every $n$ (and this is not always true), then we can choose $\varepsilon_{n}=0$, (or $\left.\varepsilon_{n}^{*}=0\right), n=1,2, \cdots$, and consider in (4) only the equality sign. 
The results of this paper are related to those of Huffstutler and Stein [2], [3], which are taken as special cases for certain classes of equations of the form (1).

In what follows, $D=\max _{1 \leqq i \leqq m-1}\left\{1, \sup _{t \in[0,1]}\left\{|x(t)|^{i}\right\}\right\}$.

2. Main result. THeorem. Let the function $Q$ be such that

$$
|Q(t, u)-Q(t, v)| \leqq A \sum_{k=1}^{m}\left|u^{k}-v^{k}\right|
$$

for every $(t, u, v) \in[0,1] \times(-\infty,+\infty) \times(-\infty,+\infty)$ where

$$
A \text { is }\left\{\begin{array}{l}
\text { any positive constant for } m=1 \\
\text { such that } A D<[m(m-1)]^{-1} \text { for } m>1,
\end{array}\right.
$$

and suppose further that a sequence of polynomials $P_{n}$, (or $\left.P_{n}^{*}\right)$, satisfies the given initial condition and the first of (4), (the second of 4), for every $n$. Then the sequence $P_{n}$, (or $P_{n}^{*}$ ), converges uniformly to the solution $x(t)$ on [0.1]. In addition, the sequence $P_{n}^{\prime}$, (or $P_{n}^{* \prime}$ ), converges uniformly (w.r.t. the $L_{p}$ norm) to the derivative $x^{\prime}(t)$.

Proof. Case I (Uniform norm). We show first that $\lim _{n \rightarrow \infty} L\left(P_{n}(t)\right)=$ $L(x(t))$ uniformly on $[0,1]$. In fact, there exists a sequence of polynomials $S_{n}$, of degree less than or equal to $n$, such that $S_{n}(0)=0$, and $\lim _{n \rightarrow \infty} S_{n}^{(i)}(t)=x^{(i)}(t), i=0,1$, uniformly on [0,1]. We can take, for example, the Bernstein polynomials

$$
S_{n} \equiv B_{n}(x ; t)=\sum_{k=0}^{n} x\left(\frac{k}{n}\right)\left(\begin{array}{l}
n \\
k
\end{array}\right) t^{k}(1-t)^{n-k} .
$$

Thus, by use of (3), we obtain

$$
\begin{aligned}
\left\|L(x)-L\left(P_{n}\right)\right\| & \leqq \mu_{n}+\varepsilon_{n} \leqq\left\|L(x)-L\left(S_{n}\right)\right\|+\varepsilon_{n} \\
& \leqq\left\|x^{\prime}-S_{n}^{\prime}\right\|+\left\|Q(t, x)-Q\left(t, S_{n}\right)\right\|+\varepsilon_{n} \\
& \leqq\left\|x^{\prime}-S_{n}^{\prime}\right\|+A \sum_{n=1}^{m}\left\|x^{k}-S_{n}^{k}\right\|+\varepsilon_{n},
\end{aligned}
$$

and the sequences in the last member of (6) tend to zero, which shows the uniform convergence of $L\left(P_{n}(t)\right)$.

We show next that the sequence $P_{n}$ is uniformly bounded on $[0,1]$. Let $u_{n}(t)=x(t)-P_{n}(t)$ and $F_{n}(t)=L(x(t))-L\left(P_{n}(t)\right), t \in[0,1]$; then from (1) we obtain

$$
\begin{aligned}
F_{n}(t) & =L(x)-L\left(x-u_{n}\right)=x^{\prime}+Q(t, x)-\left[x^{\prime}-u_{n}^{\prime}+Q\left(t, x-u_{n}\right)\right] \\
& =u_{n}^{\prime}+\left[Q(t, x]-Q\left(t, x-u_{n}\right)\right]
\end{aligned}
$$

which gives 


$$
\begin{aligned}
\left|u_{n}(t)\right| \leqq & \int_{0}^{1}\left|F_{n}(s)\right| d s+\int_{0}^{t}\left|Q(s, x(s))-Q\left(s, x(s)-u_{n}(s)\right)\right| d s \\
& \leqq \int_{0}^{1}\left|F_{n}(s)\right| d s+A \int_{0}^{t}\left[\sum_{k=1}^{m}\left|x^{k}(s)-\left(x(s)-u_{n}(s)\right)^{k}\right|\right] d s \\
& \leqq A_{n}+A \int_{0}^{t}\left[\sum_{k=1}^{m} \mid x^{k}(s)-\left(x^{k}(s)-k x^{k-1}(s) u_{n}(s)+\cdots\right.\right. \\
& \left.\left.+(-1)^{k} u_{n}^{k}(s)\right) \mid\right] d s \\
& \leqq A_{n}+A \int_{0}^{t}\left[\sum_{k=1}^{m}\left(k|x(s)|^{k-1}\left|u_{n}(s)\right|+\cdots+\left|u_{n}(s)\right|^{k}\right)\right] d s \\
& \leqq A_{n}+A D \int_{0}^{t}\left[\sum _ { k = 1 } ^ { m } \left(k\left|u_{n}(s)\right|+(k(k-1) / 2 !)\left|u_{n}(s)\right|^{2}+\cdots\right.\right. \\
& \left.\left.\quad+\left|u_{n}(s)\right|^{k}\right)\right] d s \\
\leqq & +A D \int_{0}^{t}\left[\sum_{k=1}^{m}\left(1+\left|u_{n}(s)\right|\right)^{k}\right] d s \\
\leqq & +m A D \int_{n}^{t}\left(1+\left|u_{n}(s)\right|\right)^{m} d s,
\end{aligned}
$$

where $A_{n}$ is a constant determined by (6).

If $m=1$, then the uniform boundedness follows easily from (7) by a direct application of Gronwall's inequality ([1], p. 8). Let $m>1$, $q_{n}(t)=\int_{0}^{t}\left(1+\left|u_{n}(s)\right|\right)^{m} d s$, and choose $\varepsilon>0$ such that $A D<\left[(1+\varepsilon)^{m-1}\right.$ $m(m-1)]^{-1}$ and $A_{n}<\varepsilon$ for every $n \geqq$ (some) $N$. Then from (7) we have

$$
\begin{aligned}
q_{n}^{\prime}(t) & \leqq\left[1+A_{n}+m A D q_{n}(t)\right]^{m} \\
& \leqq\left[1+\varepsilon+m A D q_{n}(t)\right]^{m} \quad(n \geqq N)
\end{aligned}
$$

which, dividing by the last member and integrating from 0 to $t \geqq 0$, yields

$$
(1+\varepsilon)+m A D q_{n}(t) \leqq\left[(1+\varepsilon)^{1-m}-m(m-1) A D\right]^{-1 /(m-1)},
$$

which shows the uniform boundedness of

$$
\left[q_{n}^{\prime}(t)\right]^{1 / m}-1=\left|u_{n}(t)\right|=\left|x(t)-P_{n}(t)\right|
$$

and, consequently, the uniform boundedness of the sequence $P_{n}$.

Now, we use the uniform boundedness of $P_{n}$ in order to show their convergence to the solution $x(t)$. From (1) we obtain

$$
\begin{aligned}
\left|x(t)-P_{n}(t)\right| \leqq \int_{0}^{t}\left|F_{n}(s)\right| d s+\int_{0}^{t} \mid Q\left(s, x(s)-Q\left(s, P_{n}(s)\right) \mid d s\right. \\
\leqq \int_{0}^{t}\left|F_{n}(s)\right| d s+A \sum_{k=1}^{m} \int_{0}^{t}\left|x-P_{n}\right| \mid x^{k-1}+x^{k-2} P_{n} \\
+\cdots+P_{n}^{k-1} \mid d s \\
\leqq \int_{0}^{t}\left|F_{n}(s)\right| d s+m A K \int_{0}^{t}\left|x(s)-P_{n}(s)\right| d s
\end{aligned}
$$


where $K=\max _{1 \leqq k \leqq m} \sup _{t \in[0,1]}\left\{\left|x^{k-1}(t)+x^{k-2}(t) P_{n}(t)+\cdots+P_{n}^{k-1}(t)\right|\right\}$ independent of $n$, due to the uniform boundedness of the $P_{n}$ 's. Thus, an application of Gronwall's inequality in (10) gives

$$
\left|x(t)-P_{n}(t)\right| \leqq\left(\int_{0}^{t}\left|F_{n}(s)\right| d s\right) . \quad e^{m A K} \leqq\left(\int_{0}^{1} F_{n}(t) d t\right) e^{m A K} .
$$

Since the right side $\rightarrow 0$ as $n \rightarrow \infty$, this proves the uniform convergence of the sequence $P_{n}$.

The proof of the uniform convergence of the derivatives of the $P_{n}$ 's follows from

$$
\begin{aligned}
\left|x^{\prime}(t)-P_{n}^{\prime}(t)\right| \leqq & \left|L(x)-L\left(P_{n}\right)\right|+\left|Q(t, x)-Q\left(t, P_{n}\right)\right| \\
\leqq & \left|F_{n}(t)\right|+A \sum_{k=1}^{m}\left|x^{k}(t)-P_{n}^{k}(t)\right| \\
\leqq & \left|F_{n}(t)\right|+A \sum_{k=1}^{m}\left[\left|x(t)-P_{n}(t)\right| \mid x^{k-1}(t)+x^{k-2}(t) P_{n}(t)\right. \\
& \left.\quad+\cdots+P_{n}^{k-1}(t) \mid\right] \\
& \leqq\left|F_{n}(t)\right|+m A K\left|x(t)-P_{n}(t)\right|,
\end{aligned}
$$

and the final expression $\rightarrow 0$ as $n \rightarrow \infty$.

Case II $\left(L_{p}\right.$ norm). Suppose that $P_{n}^{*}$ is a sequence of polynomials which satisfies the second of (4). Then (6) holds with $P_{n}$ replaced by $P_{n}^{*}$, and $\|\cdot\|$ by $\|\cdot\|_{p}$, since the uniform convergence of $S_{n}^{(i)}, i=0,1$, implies their convergence w.r.t. the $L_{p}$ norm. Thus, $L\left(P_{n}^{*}\right)$ converges w.r.t. the $L_{p}$ norm to $L(x)$. In order to show that the $P_{n}^{*}$ 's are uniformly bounded, choose $\varepsilon^{*}>0, N$ such that $A D<\left[\left(1+\varepsilon^{*}\right)^{m-1} m(m-\right.$ $1)]^{-1}$ and $\left\|L(x)-L\left(P_{n}^{*}\right)\right\|_{p}<\varepsilon^{*}$ for every $n \geqq N$. Then we obtain (as in (7))

$$
\begin{aligned}
& \left|u_{n}^{*}(t)\right| \leqq \int_{0}^{t}\left|F_{n}^{*}(s)\right| d s+m A D \int_{0}^{t}\left(\left|u_{n}^{*}(s)\right|+1\right)^{m} d s \\
& \leqq\left[\int_{0}^{t}\left|F_{n}^{*}(s)\right|^{p} d s\right]^{1 / p}+m A D \int_{0}^{t}\left(\left|u_{n}^{*}(s)\right|+1\right)^{m} d s \\
& \leqq \varepsilon^{*}+m A D \int_{0}^{t}\left(\left|u_{n}^{*}(s)\right|+1\right)^{m} d s,
\end{aligned}
$$

and the proof follows as in the case of the uniform norm. The uniform convergence of the $P_{n}^{*}$ 's follows from an inequality similar to (10), and the $L_{p}$ norm convergence of the derivatives of the $P_{n}^{*}$ 's from

$$
\begin{aligned}
\left\|u_{n}^{* \prime}(t)\right\|_{p} & \leqq\left\|F_{n}^{*}\right\|_{p}+\left\|Q(t, x)-Q\left(t, x-u_{n}^{*}\right)\right\|_{p} \\
& \leqq\left\|F_{n}^{n}\right\|_{p}+A D E \sum_{k=1}^{m}\left\|u_{n}^{*}\right\|_{p}
\end{aligned}
$$

( $E$ is a suitable constant), and the final expression $\rightarrow 0$ as $n \rightarrow \infty$. 
It should be mentioned here that if $\lim _{n \rightarrow \infty} n^{2} \max _{t \in[0,1]}\left|P_{n}^{*}(t)-x(t)\right|=$ 0 , then the sequence $P_{n}^{* \prime}$ converges uniformly to $x^{\prime}(t)$, and this can be shown as in [2].

3. Example. Consider the differential equation

$$
\left(^{*}\right) \quad x^{\prime}+(3 / 37) t^{2} x^{2} /\left(1+x^{2}\right)-(1 / 16)\left[t^{2} /\left(1+t^{2}\right)\right] x^{4} /\left(1+x^{4}\right)=(t-1 / 2)^{1 / 3} .
$$

Here we have $m=4$, and

$$
\begin{aligned}
|Q(t, u)-Q(t, v)| & \leqq(3 / 37)\left|u^{2}-v^{2}\right|+(1 / 16)\left|u^{4}-v^{4}\right| \\
& \leqq(3 / 37)\left(\left|u^{2}-v^{2}\right|+\left|u^{4}-v^{4}\right|\right)
\end{aligned}
$$

i.e., $A=3 / 37$. If $x(t)$ is a solution of $\left(^{*}\right)$ with $x(0)=0$, then we have

$$
\begin{aligned}
|x(t)| & \leqq(3 / 37) \int_{0}^{1} t^{2} d t+(1 / 16) \int_{0}^{1}\left[t^{2} /(1+t)^{2}\right] d t+\int_{0}^{1}(t-1 / 2)^{1 / 3} d t \\
& <3 / 37+1 / 16<1
\end{aligned}
$$

and, consequently, we have $D=1$. Moreover, if we suppose the existence of a second solution $y(t)$ of $\left(^{*}\right)$ with $y(0)=0$, then we get

$$
\begin{aligned}
& |Q(t, x)-Q(t, y)| \leqq A\left(\left|x^{2}-y^{2}\right|+\left|x^{4}-y^{4}\right|\right) \\
& \quad \leqq A|x-y|\left(|x+y|+|x|^{3}+x^{2}|y|+|x| y^{2}+|y|^{3}\right) \\
& \quad \leqq 6 A|x-y| .
\end{aligned}
$$

Now, integration of $x^{\prime}-y^{\prime}=-[Q(t, x)-Q(t, y)]$ and use of (13) and Gronwall's inequality, shows the uniqueness of the solution $x(t), t \in$ $[0,1]$ of $\left(^{*}\right)$ with $x(0)=0$. Furthermore, $A D=3 / 37<[m(m-1)]^{-1}=$ $1 / 12$, and the theorem applies to the equation $\left(^{*}\right)$. This example is not contained in any of the results in [4], since the function $Q-R$ is not analytic for $-1 \leqq t \leqq 1$ and all $x$.

The authors wish to thank the referee for some helpful suggestions.

\section{REFERENCES}

1. A. Halanay, Differential Equations, Stability Oscillations and Time Lags, Academic Press, 1966.

2. R. G. Huffstutler and F. Max Stein, The best approximate solution of the extended Riccati equation using the $L_{q}$ norm, Rend. Circ. Mat. Palermo, 16 (1967), 373-381.

3. - The approximate solution of certain nonlinear differential equations, Proc. Amer. Math. Soc., 19 (1968), 998-1002.

4. - The approximate solution of $y^{\prime}=F(x, y)$, Pacific J. Math., 24 (1968), 283-289.

Received September 16, 1970 and in revised form November 10, 1970.

Michigan State University

AND

UnIVERsity of Athens 



\section{PACIFIC JOURNAL OF MATHEMATICS}

\section{EDITORS}

H. SAMELSON

Stanford University

Stanford, California 94305

C. R. HOBBY

University of Washington

Seattle, Washington 98105
J. DugundJI

Department of Mathematics

University of Southern California

Los Angeles, California 90007

RICHARD ARENS

University of California

Los Angeles, California 90024

\section{ASSOCIATE EDITORS}

E. F. BeCKENBACH

B. H. NeumanN

F. WOLF

K. YosHIDA

\section{SUPPORTING INSTITUTIONS}

UNIVERSITY OF BRITISH COLUMBIA

CALIFORNIA INSTITUTE OF TECHNOLOGY

UNIVERSITY OF CALIFORNIA

MONTANA STATE UNIVERSITY

UNIVERSITY OF NEVADA

NEW MEXICO STATE UNIVERSITY

OREGON STATE UNIVERSITY

UNIVERSITY OF OREGON

OSARA UNIVERSITY
UNIVERSITY OF SOUTHERN CALIFORNIA STANFORD UNIVERSITY

UNIVERSITY OF TOKYO

UNIVERSITY OF UTAH

WASHINGTON STATE UNIVERSITY

UNIVERSITY OF WASHINGTON

AMERICAN MATHEMATICAL SOCIETY

NAVAL WEAPONS CENTER

Printed in Japan by International Academic Printing Co., Ltd., Tokyo, Japan 


\section{Pacific Journal of Mathematics}

\section{Vol. 40, No. $1 \quad$ September, 1972}

Alex Bacopoulos and Athanassios G. Kartsatos, On polynomials

approximating the solutions of nonlinear differential equations........

Monte Boisen and Max Dean Larsen, Prüfer and valuation rings with zero

divisors ..........................................

James J. Bowe, Neat homomorphisms

David W. Boyd and Hershy Kisilevsky, The Diophantine equation

$$
u(u+1)(u+2)(u+3)=v(v+1)(v+2) \ldots \ldots \ldots \ldots \ldots \ldots \ldots
$$

George Ulrich Brauer, Summability and Fourier analysis ...............

Robin B. S. Brooks, On removing coincidences of two maps when only one,

rather than both, of them may be deformed by a homotopy ............

Frank Castagna and Geert Caleb Ernst Prins, Every generalized Petersen

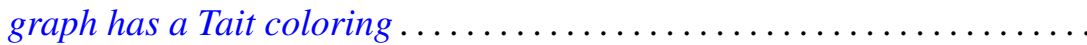

Micheal Neal Dyer, Rational homology and Whitehead products ..........

John Fuelberth and Mark Lawrence Teply, The singular submodule of a

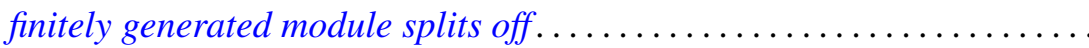

Robert Gold, $\Gamma$-extensions of imaginary quadratic fields ............ 83

Myron Goldberg and John W. Moon, Cycles in k-strong tournaments.......

Darald Joe Hartfiel and J. W. Spellmann, Diagonal similarity of irreducible

matrices to row stochastic matrices...............

Wayland M. Hubbart, Some results on blocks over local fields ..

Alan Loeb Kostinsky, Projective lattices and bounded homomorphisms....

Kenneth O. Leland, Maximum modulus theorems for algebras of operator

valued functions ...

Jerome Irving Malitz and William Nelson Reinhardt, Maximal models in the

language with quantifier "there exist uncountably many" ..

John Douglas Moore, Isometric immersions of space forms in space

forms.

Ronald C. Mullin and Ralph Gordon Stanton, A map-theoretic approach to

Davenport-Schinzel sequences ....................

Chull Park, On Fredholm transformations in Yeh-Wiener space. .

Stanley Poreda, Complex Chebyshev alterations ..............

Ray C. Shiflett, Extreme Markov operators and the orbits of Ryff. ...

Robert L. Snider, Lattices of radicals .....................

Ralph Richard Summerhill, Unknotting cones in the topological

category ................................

Charles Irvin Vinsonhaler, A note on two generalizations of $\mathrm{QF}-3 \ldots \ldots 229$

William Patterson Wardlaw, Defining relations for certain integrally

parameterized Chevalley groups...................

William Jennings Wickless, Abelian groups which admit only nilpotent

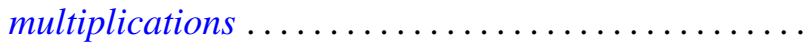

